\title{
Patient Portals
}

\section{Who uses them? What features do they use? And do they reduce hospital readmissions?}

Ashley Griffin'; Asheley Skinner1; Jonathan Thornhill2; Morris Weinberger ${ }^{1,3}$

'Department of Health Policy and Management, Gillings School of Global Public Health, University of North Carolina at Chapel Hill, 135 Dauer Drive, Chapel Hill, NC 27599;

2Learning and Diffusion Group, Center for Medicare and Medicaid Innovation, 7500 Security Boulevard, Baltimore, MD 21244;

${ }^{3}$ Center for Health Services Research in Primary Care, Department of Veterans Affairs, Durham NC 27705

\section{Keywords}

Electronic health records and systems, personal health records, patient-provider, patient portal, meaningful use

\section{Summary}

Background: Patient portals have demonstrated numerous benefits including improved patientprovider communication, patient satisfaction with care, and patient engagement. Recent literature has begun to illustrate how patients use selected portal features and an association between portal usage and improved clinical outcomes.

Objectives: This study sought to: (1) identify patient characteristics associated with the use of a patient portal; (2) determine the frequency with which common patient portal features are used; and (3) examine whether the level of patient portal use (non-users, light users, active users) is associated with 30-day hospital readmission.

Methods: My UNC Chart is the patient portal for the UNC Health Care System. We identified adults discharged from three UNC Health Care hospitals with acute myocardial infarction, congestive heart failure, or pneumonia and classified them as active, light, or non-users of My UNC Chart. Multivariable analyses were conducted to compare across user groups; logistic regression was used to predict whether patient portal use was associated with 30-day readmission.

Results: Of 2,975 eligible patients, $83.4 \%$ were non-users; $8.6 \%$ were light users; and $8.0 \%$ were active users of My UNC Chart. The messaging feature was used most often. For patients who were active users, the odds of being readmitted within 30 days was $66 \%$ greater than patients who were non-users $(p<0.05)$. There was no difference in 30 -day readmission between non-users and light users.

Conclusions: The vast majority of patients who were given an access code for My UNC Chart did not use it within 30 days of discharge. Of those who used the portal, active users had a higher odds of being readmitted within 30 days. Health care systems should consider strategies to: (1) increase overall use of patient portals and (2) target patients with the highest comorbidity scores to reduce hospital readmissions.

\section{Correspondence to:}

Ashley Griffin, MSPH

5639 Old Chapel Hill Rd. Apt. 812, Durham, NC 27707

Phone: (828) 551-2206

E-mail: ashley.griffin@alumni.unc.edu
Appl Clin Inform 2016; 7: 489-501

http://dx.doi.org/10.4338/ACI-2016-01-RA-0003

received: January 16, 2016

accepted: March 28, 2016

published: June 6, 2016

Citation: Griffin A, Skinner A, Thornhill J, Weinberger M. Patient Portals: Who uses them? What features do they use? And do they reduce hospital readmissions? Appl Clin Inform 2016; 7: 489-501 http://dx.doi.org/10.4338/ACI-2016-01-RA-0003 


\section{Background}

\subsection{Patient Portal Usage}

During the past twenty years, an increasing number of healthcare organizations have adopted patient portals in their electronic health record (EHR) systems. Patient portals provide patients access to selected health information from their health care organization's EHR, including medications, discharge summaries, lab results, immunizations, and allergies [1]. More advanced portals allow patients to send secure messages to clinical staff, access patient-specific educational materials, schedule appointments, request prescription refills, and manage bills [2]. Patient portals can facilitate interactions between patients and providers that promote informed decision-making and patient engagement. Thus, patient portals are associated with improved communication and satisfaction with care [1]. Patient portals may be particularly useful to patients with multiple chronic conditions who have frequent interactions with the healthcare system [3].

Despite their many potential benefits, patient portals have been underutilized, especially by patients from racial and ethnic minorities [4]. Some reasons for low usage may include patients' lack of interest, not feeling that the portal was helpful, physicians not discussing the portal with them, or lack of a computer or Internet access [4]. Many published studies report that patient engagement has been the most beneficial through portals from large, integrated health systems that have the support and resources to adopt, implement, and maintain a patient portal $[5,30]$. Most studies show only the user volume and demographics of users within large, integrated health systems, especially in their primary clinics [6]. Furthermore, there is little known about patterns and features patients use in different health care contexts.

\subsection{Federal Incentive Programs Impact on Patient Portals}

The Health Information Technology for Economic and Clinical Health Act, which was part of the American and Recovery and Reinvestment Act of 2009, established the Meaningful Use Incentive Program to encourage the use of EHRs in the U.S. [7] CMS launched Stage 2 of the Meaningful Use program in 2014, and several of the measures provide financial incentives for providers to engage patients through a patient portal [8]. To earn the incentive, at least $50 \%$ of patients must be able to view, download, and transmit health information within 4 days of an office visit (for providers) or within 36 hours of discharge (for hospitals) [8]. Of these patients, at least 5\% must access their health information via the portal, and at least $5 \%$ of patients must send a secure electronic message to their provider. In a 2014 American Hospital Association Survey, only about half of all U.S. hospitals had the capability to provide their patients with the ability to send secure messages to patients [9]. Stage 3 of the Meaningful Use program increases the focus and requirement on interoperability, and it combines separate objectives into a single Patient Electronic Access objective with two measures. The first measure will require more than $80 \%$ of patients are provided timely electronic access (within 48 hours for providers and 36 hours for hospitals) to their health information, and the second measure will require more than $35 \%$ of patients are provided with electronic access to patient-specific educational resources [10]. Thus, patient portal usage has dramatically increased as a result of the Meaningful Use Incentive Program, and there has been increasing evidence that suggests patient portals may improve clinical outcomes [2, 14, 25-29].

In addition to Meaningful Use requirements, regulations in the Affordable Care Act (ACA) provide financial incentives to hospitals to reduce readmission rates. The Medicare Hospital Readmissions Reduction Program (HRRP), established in the ACA in 2012, imposes a penalty for patients who are readmitted to the same or another acute care hospital within 30 days of discharge, excluding planned readmissions or transfers [11]. The HRRP applies to readmissions of Medicare patients ages 65 and older with diagnoses of acute myocardial infarction (AMI), congestive heart failure (CHF) or pneumonia at all hospitals paid under the Inpatient Prospective Payment System [12]. Beginning in October 2014, the HRRP included two additional conditions: elective hip or knee replacement and chronic obstructive pulmonary disease [12]. 


\subsection{Connection between Clinical Outcomes and Patient Portals}

The Institute of Medicine identified patient-provider communication as a key component of improving the quality of patient care and health outcomes [13]. Many recent studies have evaluated the association between patient portals and clinical health outcomes [14, 25-29]. The health outcomes have been evaluated in a variety of ways, including blood pressure, LDL, HbAlc, patient knowledge, office visit rates, treatment adherence, and mortality $[14,25]$. While many of the studies showed no statistically significant differences in patient outcomes between intervention and control groups, there were significant decreases in office visits, changes in medication regimen, and better adherence to treatment among patients who used portals $[14,25]$. In studies among patients with chronic conditions (e.g., diabetes, hypertension, depression, chronic musculoskeletal pain), findings have suggested that portals engage patients in their health by providing access to tailored educational material, encouraging patient-provider communication, and providing access to self-disease management tools [14, 29]. Overall, the majority of these studies have determined a positive association between patient portals and outcomes, including improved medication adherence, chronic disease management, and disease awareness [14, 25-29]. Therefore, there is likely an association with using portals and improved patient outcomes.

In addition, a recent retrospective observational study at Kaiser Permanente found that secure patient-physician e-mail was associated with a statistically and clinically significant improvement in glycemic control, cholesterol levels, and blood pressure screening and control [3]. The majority of studies reviewed suggested that when patient portals are combined with existing health services, they can lead to improvements in clinical outcomes through four mechanisms: patient insight of personal health information, activation of information, continuity of care, and service convenience [15]. However, these outcomes have been reported from portals within large integrated delivery systems that have a system-wide EHR. In large health systems, patients have a single access point through a portal that they are able to view their medical and administrative information as well as interact with all of their providers in the health system [16].

Therefore, there are several important gaps in the literature. There is little known about the characteristics of users and functionalities used of patient portals across the healthcare landscape. Understanding the types of patients and their behaviors when using the portal may help to better connect with patients and improve their health. To date, portals seem to have the most impact on patient satisfaction, communication, and care coordination. However, few studies have examined the association between use of a patient portal and clinical outcomes throughout the health care system. The positive effects of patient portals on clinical outcomes have largely been observed in integrated health care systems with existing disease management programs, which provide a framework for portals to be effective. Many studies have mentioned "ceiling effects" due to the breadth and quality of existing programs, which may limit further improvements or outcomes [15]. Health care systems that lack existing disease management programs that emphasize care coordination may not show similar benefits of patient portals [15].

\section{Objectives}

This study seeks to bridge the gaps in the literature related to patient portals and patient outcomes. Therefore, among patients discharged from the hospital with CHF, AMI, or pneumonia, we aimed to: (1) identify patient characteristics associated with the use a patient portal, (2) determine the frequency with which common patient portal features are used; (3) examine whether the level of patient portal use (non-users, light users, active users) is associated with 30-day readmission. 


\section{Methods}

\subsection{Setting}

The University of North Carolina Health Care System (UNC Health Care) was established in 1998 and is governed as an affiliated enterprise. The original legislation included the University of North Carolina Hospitals at Chapel Hill (UNC Hospitals); as of January 2013, the organization has extended its governance to Rex Healthcare, Inc. (Rex), Chatham Hospital, Inc. (Chatham), High Point Regional Health, Caldwell Memorial, and UNC Physicians Network [17]. The current study involves patients from three of these hospitals: UNC Hospital ( 830 beds), Rex (433 beds), and Chatham (25 beds) [17]. We chose these three hospitals because they are distinct types of hospitals - teaching, community, and critical access hospital. They also each began using Epic EHR in 2014: UNC and Chatham in April and Rex in June. My UNC Chart, the patient portal for all three hospitals, gives patients controlled access to their medical records through a web browser or mobile application [18]. Specifically, My UNC Chart allows UNC-affiliated hospital patients to view selected parts of their medical record, use secure messaging to communicate with clinical staff or providers, schedule appointments, refill prescriptions, manage medical bills, as well as perform other tasks. Secure messaging is a closed-loop process, so patient-initiated messages are responded to by a non-clinical staff member, nurse, or provider, depending on the type of message. All messages are kept in the patient portal and EHR for clinical reference. There were no customizations made to My UNC Chart other than typical configuration settings at the time of this study.

\subsection{Patients}

Patients were included if they were: (1) > 18 years old; (2) diagnosed with AMI, CHF, or pneumonia at one of the three hospitals; (3) discharged alive between May 4, 2014 - November 4, 2014 (from UNC or Chatham) or August 1, 2014 - November 4, 2014 (from Rex); and (4) received an access code for My UNC Chart by the time they were discharged from the hospital. These time frames began one month following Epic Go-Live at each of the three hospitals. There was no standard protocol for how patients were introduced to the portal at the time of the study. The method by which access codes were provided to patients at the study sites varied by clinic and unit. There were standard places in outpatient and inpatient workflows where patients were provided with an access code. There was also a coordinated approach to inviting patients to sign up for the portal using tables setup in the hospital lobby, which was intended to raise patient awareness and allow them to sign up on the spot.

\subsection{Data Source}

This study used data from Epic patient medical records and Epic My UNC Chart reports. Medical record data included demographic information, dates of admission and discharge to inpatient and outpatient facilities, and primary address zip code. Portal use data came from Epic My UNC Chart reports and included a list of features used by date and time of use for each patient in the study. At the time of the study, the My UNC Chart interface contained tabs at the top that included "Messaging," "Visits," "My Medical Record," "Billing," and "Preferences." The messaging and medical advice features were found in drop down menus under "Messaging." Appointment details was found under the "Visits" tab. The five other features we analyzed in this study were found under the "My Medical Record" tab. Each time a patient clicked on the drop down menu on the tab, it corresponded to a feature and timestamp in the report. For example, when a patient clicked on the drop down menu on the "Messaging tab," the My UNC Chart report would list the messaging or medical advice feature with the time stamp.

\subsection{Measures}

Our primary outcome, hospital readmission, was defined as readmission for any reason within 30 days of discharge. 
We categorized patients into three groups reflecting their level of My UNC Chart usage - nonusers, light users, and active users. Non-users were patients who either declined the activation code or failed to login within the 30 days after their first discharge. Light and active users both logged into My UNC Chart within 30 days following their first discharge. Because there were no validated cut points to distinguish light from active users, we explored different thresholds of logins (i.e., mean or median number of logins within the 30 days after discharge, mean or median number of logins plus the use of a specific feature, and patients who logged in within a week of discharge). These analyses all contained similar patterns, but because of outliers we determined the most representative categorization of light and active users was to use a median split plus the use of the messaging feature. Light users were those who logged in fewer than eight times within the 30 days after their first discharge, and active users were those who logged in eight or more times and used the messaging feature. Reading or writing a message on My UNC Chart requires more active patient involvement, instead of simply clicking on features in the portal, so these patients were categorized as active users.

We examined patients' use of eight common portal features: messaging, medical advice message, lab tests/results, medication list, problem list, allergies, immunizations, and appointment details. The messaging feature included reading or writing any type of message in the patient's inbox, such as prescription refills, customer service requests, or clinical messages. Medical advice messages included only messages that patients sent or received from a provider or clinical staff, including all read or written messages. Messaging and medical advice messages were analyzed separately to distinguish administrative or customer service messages from medical messages. The lab tests/results, medication list, and problem list features showed information similar to that listed in the medical chart and can only be read by patients. Appointment details allowed patients to view their past and upcoming appointments; it did not allow patients to schedule their own appointments. Allergies and immunizations were grouped into one category because they were located on the same tab in My UNC Chart, so if a patient viewed allergies they also viewed immunizations. We calculated both the proportion of users that used each of these features as well as the average number of times that a feature was used within the 30 days following the patient's first discharge.

Zip code was mapped using ArcGIS software to determine the number of miles from the patient's zip code to the hospital of discharge. This allowed us to determine if patients were local or traveling from greater distances. Fifty miles to the hospital was used because, empirically, it was approximately the third quartile of the distribution of distance from patients' homes. The problem list from the patient medical record was used to calculate a Charlson Comorbidity Score [19]. Patients were categorized into one of four previously established comorbidity levels: none, low, moderate, and high [20]. Patient medical records were also used to determine if patients had an outpatient visit within 14 days after discharge to see if patients received timely follow-up care. Age, sex, and race were also used in the analysis.

\subsection{Statistical Analysis}

Analyses were performed using Stata software (version 13.0, Stata Corp, College Station, Texas, USA). To compare across groups (non-users, light users, active users), we used analysis of variance (ANOVA) (for continuous variables) and chi-square tests (for categorical variables). To compare the average number of times active and light users used specific features in the 30 days after discharge, we conducted Wilcoxon rank-sum (Mann-Whitney) tests. Then we used a logit regression model to control for age, sex, race, zip code, comorbidity score, hospital, and outpatient visit within 14 days.

\section{Results}

\subsection{Patient Characteristics}

Of 2,975 eligible patients, 2,480 (83.4\%) were non-users of My UNC Chart; the remaining patients almost equally divided between light $(8.6 \%)$ and active $(8.0 \%)$ users ( $>$ Table 1$)$. Users groups were significantly different $(\mathrm{p}<0.01)$ by race and hospital location. Most patients had high $(39 \%)$ or moderate $(38 \%)$ Charlson Comorbidity scores. The mean age was approximately 66 years old. When 
comparing active and light users, active users had a higher proportion of Caucasian patients, higher Charlson Comorbidity scores, and a higher proportion of patients admitted to an academic medical center, UNC Hospital. Approximately 15\% of patients were readmitted within 30 days; $15 \%$ were non-users of My UNC Chart, 13\% were light users, and 21\% were active users ( $\downarrow$ Table 1 ).

\subsection{My UNC Chart Commonly Used Features}

My UNC Chart users primarily used eight features: messaging, medical advice message, lab tests/results, medication list, problem list, allergies, immunizations, and appointment details ( $\triangleright$ Table 2). The messaging feature was used by $100 \%$ of active users, as defined by the authors' categorization of active users, and used by $59 \%$ of light users in the month following discharge from the hospital. Active and light users used most of the features in the same proportions, excluding medical advice messages and appointment details. Only about $18 \%$ of light users utilized the medical advice function, compared to $66 \%$ of active users. Approximately $79 \%$ of active users viewed the appointment details function, whereas only $17 \%$ of light users viewed the function in the month after discharge.

- Table 3 shows the mean number of times that active and light users utilized the eight most common features in MyUNCchart, as well as the number of logins, during the 30 days after their first discharge. Light users logged in to their account on average about three times per month, whereas active users logged in on average 34 times per month. Light users viewed or sent messages 9 times per month, whereas active users used the messaging feature about 108 times per month. Light users viewed their lab tests/results on average about 14 times per month, whereas active users viewed their results 76 times per month in the month following discharge. The high mean averages for active users may be the result of multiple people using the account, such as family members or caregivers. Active users accessed common functionalities significantly $(\mathrm{p}<0.01)$ more often than light users.

\subsection{Association between My UNC Chart Use and 30 Day Readmissions}

There was a statistically significant difference $(\mathrm{p}<0.05)$ in 30 -day readmission between non-users and active users of My UNC Chart ( Table 4). For patients who were active users, the odds of being readmitted within 30 days was $66 \%$ higher than patients who were non-users, holding all other variables constant in the model. There was no significant difference in 30-day readmission between non-users and light users. For patients with a moderate Charlson Comorbidity score, the odds of being readmitted within 30 days was 2.2 times larger $(\mathrm{p}<0.01)$ than for the odds of a patient with no comorbidity score, on average holding all other variables constant. For patients with a high Charlson Comorbidity score, the odds of being readmitted within 30 days was 3.3 times larger $(\mathrm{p}<0.01)$ than for the odds of a patient with no comorbidity score. In addition, for patients who did not have an outpatient visit within 14 days, the odds of being readmitted within 30 days was $37 \%$ more likely $(\mathrm{p}<0.05)$ than patients who had a follow-up visit within 14 days.

Out of the 495 My UNC Chart users, approximately $21 \%$ of active users were readmitted to the hospital, whereas $13 \%$ of light users were readmitted to the hospital within 30 days ( $>$ Table 5). Similarly, $21 \%$ of active users who used the messaging feature were readmitted within 30 days, whereas only $12 \%$ of light users who used the messaging feature were readmitted. There is a statistically significant difference between active and light users being readmitted within 30 days for patients using the messaging feature $(\mathrm{p}<0.05)$, lab tests $(\mathrm{p}<0.05)$ and medication list features $(\mathrm{p}<0.01)$.

\section{Conclusions}

Despite the rapid proliferation of patient portals, little is known about their use by, or effect on, patients. The majority of studies reported the user volume and demographics of patient portal users within only one type of health care delivery setting, especially in primary care settings [6]. Our study extends prior research by studying three settings within a single health care system - an academic medical center, community hospital, and a critical access hospital. Moreover, the patient population used in this study differs from previous studies because we focused on patients discharged from the 
hospital, a group that may benefit most from features in patient portals. In addition, because our study was conducted only one month after the three study hospitals switched to a new EHR and patient portal, our patient population may represent early adopters to new technology who may have different motivations or abilities than the general population.

Our first finding was that, among patients who received an access code for My UNC Chart at hospital discharge, only $16 \%$ used the patient portal within 30 days of discharge. This is concerning because previous studies have demonstrated the value in providing patients access to their EHR [3, $6,14,15,25-29]$. There are many perceived barriers to patients using portals, including privacy and security issues, initiation concerns, and knowledge barriers of when/how to use it $[4,21,31,32]$. In a recent mixed-methods study at a Veterans Affairs Medical Center, patients reported learning that their messages were not going directly to their primary care provider and being accessed by multiple members of the clinical team [21]. These patients also noted the resistance of clinical staff to sending and receiving messages from patients, which discouraged patients from using portals [21]. Other studies have reported patients having a lack of interest or negative attitude toward using portals [4]. However, with an increasing number of patients using digital devices, further adoption of portals is likely to increase in a wide range of health care settings in the future [33]. To increase enrollment and usage, providers and staff may need to communicate the relevance of using the portal in a clinical context (e.g., refilling prescriptions, sending messages to report their symptoms) if patients are to perceive how portals will be beneficial to them.

The 495 patients who used My UNC Chart were older, sicker, and more likely to be Caucasian than non-users. This is consistent with prior studies showing that healthy patients, patients less than 35 years of age, and ethnic minorities are the least likely to use patient portals [6,22,23]. Notably, although we cannot determine who actually used the portal (patient or someone the patient trusted with log-in information), these are characteristics of patients who may have more chronic conditions and greater health care utilization (including readmissions). If so, increased access to the portal may be most important for patients with more complex health conditions.

The most common features used of My UNC Chart were messaging, medical advice requests, lab results/tests, problem list, medication list, allergies, immunizations, and appointment details. This is consistent with previous literature [6]. In addition, other studies also showed regular users scheduling appointments and prescription refills [6]. In our study, prescription refills were captured under the messaging feature. At the time our study was conducted, patients were unable to schedule their own appointment, but they were able to request appointments as well as view past and upcoming appointments through the appointment details feature. The messaging feature was the most commonly used feature in this study. This may be because it is one of the objectives for Meaningful Use Stage 2 and 3, so there is increased awareness of clinical staff to encourage patients to send messages. Furthermore, most patients in this study had medium or high Charlson comorbidity scores, so the features offered through My UNC Chart, especially messaging, could provide value for sicker patients. Previous studies have shown that patients with chronic conditions who are able to communicate with their providers through secure electronic messaging have been associated with improved outcomes [3]. Thus, these findings suggest that high-risk patients may have the most to benefit from the features in patient portals.

Contrary to our hypothesis, the odds of being readmitted within 30 days was $66 \%$ greater for active users than patients who were non-users, on average holding all other variables constant in the model. There are several plausible explanations. First, patients who are more engaged with their care and their doctor are more likely to have complications identified. This may result in a hospital readmission for an appropriate reason if the patient needs follow-up care at the hospital. Second, patients who have more interactions with the health care system have greater opportunities to enroll and utilize the portal. Because our patient population was sicker, they probably had multiple visits within the health care system. In addition, sicker patients may be more likely to use portals. A recent study showed that patients with one or more chronic health conditions may be more likely to access and use portals compared to patients without chronic conditions [1]. This may well have occurred in our current study, as active users had higher scores on the Charlson Comorbidity Index than light and non-users, which puts them at higher risk of readmission. Active users were also much more likely to be seen at an academic medical center, UNC Hospital, which may also indicate that they have more serious health complications. Finally, a multi-site randomized controlled trial found that im- 
proving access to care for clinically vulnerable Veterans discharged from the hospital increased readmissions [24]. Perhaps this is further evidence that attempts to reduce readmissions are challenging and sometimes counter-intuitive.

Additionally, this study showed an association between selected portal features used and readmission within 30 days. We expected a higher proportion of active users to use the features, but like our previous finding, it was contrary to our beliefs that active users who used the messaging feature, as well as other features, were more likely to be readmitted within 30 days. Similarly, this may be because our patient population was sicker and more engaged with their health, resulting in follow-up care.

\subsection{Limitations}

This study had several limitations. First, the three study hospitals switched to a new EHR and patient portal one month prior to the time the study began. This major system-wide change may have reduced the emphasis by the health care system to increase patients' use of the portal. Second, the lower percentages of active and light users at Chatham and Rex Hospital could be due to those patients having access to other portals that were not associated with UNC Health Care, and being encouraged to use other portals by the providers offering them. Third, we lacked the data to explore how patients received an access code and the patient-provider communication outside of the portal, such as patients using the telephone or e-mail to contact providers. We could not tell whether the patient or a caregiver/family members accessed the patient's My UNC Chart. In addition, some features within My UNC Chart were not available during the time of this study, such as education materials and scheduling appointments, even though patients could view upcoming and past appointment details. Fourth, it is possible that the relationship may differ across the three target diagnoses; however, our sample size did not allow us to conduct separate analyses for each diagnosis. Fifth, this study was conducted in a single health care system, which limits generalizability of our findings. Finally, the three user groups may differ on unmeasured confounders. Unfortunately, we lacked the data to address any selection bias due to the baseline differences.

\subsection{Implications}

Despite these limitations, this study has implications for the use of patient portals in health care settings across the U.S. Because patients who were more engaged in their health through a patient portal were more likely to be readmitted within 30 days, targeting patients who are at higher risk of being readmitted may be important during discharge planning. Future interventions could encourage care managers to send additional educational information to high-risk patients following discharge. Because we found an association between readmission, comorbidity status, and timely outpatient visit, active portal use may be a proxy for more severe conditions. Thus, engaging these high-risk patients within the first two weeks after discharge through the portal may be important to schedule and remind patients of their follow up visit. In addition, encouraging patients to use specific functions, such as messaging, may help educate and empower them in their health. In turn, this may help providers communicate more effectively with patients, which may improve the process and outcomes of care. On the other hand, as health systems respond to incentives for value-based care and managing overall population health, understanding the role of EHRs and portals is critical. Understanding how portals are being implemented and how patients may have access to multiple portals, such as those from other healthcare facilities or pharmacies is critical for improving communication with patients and their outcomes. In particular, EHR systems would do well to monitor how well-intentioned efforts to promote communication through patient portals effects outcomes such as 30-day readmissions. Future research should determine the exact components of portals that influence readmission, including those not available to our patients.

This is one of the first studies to date that seeks to bridge the gap between patient-level measures and clinical outcomes. This study provides insights on characteristics of patients who use patient portals, as well as the specific features that they access. In addition, we found that, among patients discharged from the hospital, active users had higher odds of readmission. It will be important to understand whether this finding results from active users being more engaged with their care spe- 
cifically because they are sicker and/or at increased risk of readmission. Further research is necessary to determine the long term outcomes of patients who utilize portals.

\section{Clinical Relevance Statement}

This research describes the patterns and features of patient portal usage in different hospital settings, which may assist with designing new interventions through the patient portal to facilitate patient engagement. We suggest strategies for practioners to increase patient portal enrollment and usage by emphasizing the importance and benefits for patients within clinical settings. Fur-

thermore, these findings can be used in practice to develop long term strategies to better engage patients, especially those with chronic conditions, to improve clinical outcomes.

\section{Conflicts Of Interest}

The authors report no conflicts of interests in the research.

\section{Protection Of Human Subjects}

This study was per-formed in compliance with the World Medical Association Declaration of Helsinki on Ethical Principles for Medical Research Involving Human Subjects, and was reviewed by UNC Institutional Review Board.

\section{Acknowledgements}

We thank the reviewers for their detailed and helpful comments on the manuscript. 
Table 1 Patient Characteristics (Mean \pm SD)

\begin{tabular}{|c|c|c|c|c|}
\hline Predictors & $\begin{array}{l}\text { Overall } \\
(\mathrm{N}=2,975)\end{array}$ & $\begin{array}{l}\text { Non-users } \\
(\mathrm{N}=2,480)\end{array}$ & $\begin{array}{l}\text { Light users } \\
(\mathrm{N}=257)\end{array}$ & $\begin{array}{l}\text { Active users } \\
(\mathrm{N}=238)\end{array}$ \\
\hline Age & $66.31(15.68)$ & $66.70(15.55)$ & $64.14(16.16)$ & $64.54(16.24)$ \\
\hline Sex (Male) & 52.17 & 51.73 & 56.42 & 52.10 \\
\hline $\begin{array}{l}\text { Race } \\
\text { - Caucasian } \\
\text { - African American } \\
\text { - Other }\end{array}$ & $\begin{array}{l}66.50 \\
29.63 \\
3.87\end{array}$ & $\begin{array}{l}64.36^{* *} \\
31.64 \\
4.00\end{array}$ & $\begin{array}{l}72.76^{* *} \\
23.35 \\
2.72\end{array}$ & $\begin{array}{l}81.93^{* *} \\
15.55 \\
1.26\end{array}$ \\
\hline Zip Code (Within 50 miles) & 79.58 & 79.41 & 78.60 & 82.35 \\
\hline $\begin{array}{l}\text { Comorbidity Score } \\
\text { - None (0) } \\
\text { - Low }(1-2) \\
\text { - Moderate (3-4) } \\
\text { - High }(\geq 5)\end{array}$ & $\begin{array}{l}7.90 \\
14.12 \\
38.29 \\
39.70\end{array}$ & $\begin{array}{l}7.46 \\
13.99 \\
37.78 \\
40.77\end{array}$ & $\begin{array}{l}12.06 \\
14.79 \\
40.47 \\
32.68\end{array}$ & $\begin{array}{l}7.98 \\
14.71 \\
41.18 \\
36.13\end{array}$ \\
\hline $\begin{array}{l}\text { Hospital Location } \\
\text { - UNC } \\
\text { - Rex } \\
\text { - Chatham }\end{array}$ & $\begin{array}{l}53.04 \\
44.24 \\
2.72\end{array}$ & $\begin{array}{l}49.64^{* *} \\
47.42 \\
2.94\end{array}$ & $\begin{array}{l}61.48^{* *} \\
36.19 \\
2.33\end{array}$ & $\begin{array}{l}79.41 * * \\
19.75 \\
0.84\end{array}$ \\
\hline Readmission within 30 Days & 15.50 & $15.20^{*}$ & $13.23^{*}$ & $21.01 *$ \\
\hline
\end{tabular}

${ }^{* *} p<0.01 * p<0.05$

\begin{tabular}{|l|l|l|}
\hline & $\begin{array}{l}\text { Light Users } \\
(\mathrm{N}=\mathbf{2 5 7})\end{array}$ & $\begin{array}{l}\text { Active Users } \\
(\mathrm{N}=\mathbf{2 3 8})\end{array}$ \\
\hline Messaging & 58.87 & 100 \\
\hline Medical Advice Message & 18.29 & 66.64 \\
\hline Lab Tests/Results & 79.77 & 97.48 \\
\hline Problem List & 75.49 & 92.01 \\
\hline Medication List & 75.88 & 92.44 \\
\hline Appointment Details & 17.51 & 78.99 \\
\hline Immunizations \& Allergies & 71.60 & 89.50 \\
\hline
\end{tabular}

Table 2

Proportions of Active and Light My UNC Chart User Activity during 30 Days After Discharge

\begin{tabular}{|l|l|l|}
\hline & $\begin{array}{l}\text { Light Users } \\
(\mathrm{N}=257)\end{array}$ & $\begin{array}{l}\text { Active Users } \\
(\mathrm{N}=238)\end{array}$ \\
\hline Login & $3.40^{* *}(2.39)$ & $34.35^{* *}(40.55)$ \\
\hline Messaging & $8.87^{* *}(20.63)$ & $108.64^{* *}(123.55)$ \\
\hline Medical Advice Message & $0.40^{* *}(1.06)$ & $5.52^{* *}(10.37)$ \\
\hline Lab Tests/Results & $14.19^{* *}(21.29)$ & $76.39^{* *}(139.26)$ \\
\hline Problem List & $2.56^{* *}(2.88)$ & $9.02^{* *}(13.10)$ \\
\hline Medication List & $2.39^{* *}(2.87)$ & $8.42^{* *}(12.40)$ \\
\hline Appointment Details & $0.35^{* *}(1.11)$ & $7.83^{* *}(20.82)$ \\
\hline Immunizations \& Allergies & $1.98^{* *}(2.30)$ & $6.53^{* *}(9.89)$ \\
\hline
\end{tabular}

Table 3

Average My UNC Chart User Activity During 30 Days After Discharge 


\begin{tabular}{|c|c|}
\hline Predictors & Odds Ratio (SE) \\
\hline $\begin{array}{l}\text { My UNC Chart User (Non-user: Referent) } \\
\text { Light User } \\
\text { Active User }\end{array}$ & $\begin{array}{l}-- \\
1.14(0.22) \\
1.66^{*}(0.40)\end{array}$ \\
\hline Age & $0.99(0.005)$ \\
\hline Sex (Male: Referent) & $1.03(0.11)$ \\
\hline $\begin{array}{l}\text { Race (Caucasian: Referent) } \\
\text { - African American } \\
\text { - Other }\end{array}$ & $\begin{array}{l}-- \\
0.96(0.11) \\
0.79(0.23)\end{array}$ \\
\hline Zip Code (Within 50 miles: Referent) & $0.78(0.11)$ \\
\hline $\begin{array}{l}\text { Comorbidity Score (None: } 0 \text { ) } \\
\text { - Low }(1-2) \\
\text { - Moderate (3-4) } \\
\text { - High }(\geq 5)\end{array}$ & $\begin{array}{l}-- \\
1.94^{*}(0.54) \\
2.19^{* *}(0.63) \\
3.30^{* *}(1.00)\end{array}$ \\
\hline $\begin{array}{l}\text { Hospital Location (UNCH: Referent) } \\
\text { - Rex } \\
\text { - Chatham }\end{array}$ & $\begin{array}{l}- \\
0.75^{*}(0.08) \\
1.65(0.44)\end{array}$ \\
\hline $\begin{array}{l}\text { Outpatient Visits within } 14 \text { Days (No visit with- } \\
\text { in } 14 \text { days: Referent) }\end{array}$ & $1.37^{* *}(0.15)$ \\
\hline
\end{tabular}

\begin{tabular}{|l|l|l|}
\hline & $\begin{array}{l}\text { Light Users } \\
(\mathrm{N}=257)\end{array}$ & $\begin{array}{l}\text { Active Users } \\
(\mathrm{N}=238)\end{array}$ \\
\hline Readmission within 30 Days & $13.10^{*}$ & $20.99^{*}$ \\
\hline Messaging & $12.16^{*}$ & $21.01^{*}$ \\
\hline Medical Advice Message & 14.89 & 20.50 \\
\hline Lab Tests/Results & $12.50^{*}$ & $21.10^{*}$ \\
\hline Problem List & 14.95 & 22.37 \\
\hline Medication List & $12.82^{* *}$ & $22.73^{* *}$ \\
\hline Appointment Details & 13.33 & 21.81 \\
\hline Immunizations \& Allergies & 13.59 & 23.00 \\
\hline
\end{tabular}

${ }^{* *} p<0.01 * p<0.05$
Table 4

Logistic Regression Analysis of 30-Day Readmission on Type of My UNC Chart User $(\mathrm{N}=2,962)^{1}$

Table 5

30 Day Readmission Outcomes of My UNC Chart Users by Feature 


\section{References}

1. Wade-Vuturo AE, Mayberry LS, Osborn CY. Secure messaging and diabetes management: Experiences and perspectives of patient portal users. Journal of the American Medical Informatics Association 2013; 20: 519-525. Available from: http://www.ncbi.nlm.nih.gov/pmc/articles/PMC3628058/

2. Kruse CS, Bolton K, Freriks G. The Effect of Patient Portals on Quality Outcomes and Its Implications to Meaningful Use: A Systematic Review. J Med Internet Res 2015; 17(2): e44. Available from: http://www. ncbi.nlm.nih.gov/pmc/articles/PMC4342639/

3. Zhou YY, Kanter MH, Wang JJ, Garrido T. Improved quality at kaiser permanente through e-mail between physicians and patients. Health Affairs 2010; 29: 71370-71375. Available from: http://content.healthaffairs.org/content/29/7/1370.abstract

4. Goel MS, Brown TL, Williams A, Cooper AJ, Hasnain-Wynia R, Baker DW. Patient reported barriers to enrolling in a patient portal. Journal of the American Medical Informatics Association 2011; 18: i8-i12. Available from:http://www.ncbi.nlm.nih.gov/pmc/articles/PMC3241181/

5. Krist AH, Woolf SH, Bello GA, Sabo TR, Longo DR, Kashiri P, Etz RS, Loomis J, Rothemich SF, Peele JE, Cohn J. Engaging Primary Care Patients to Use a Patient-Centered Personal Health Record. Ann Fam Med 2014; 12: 418-426. Available from: http://www.ncbi.nlm.nih.gov/pmc/articles/PMC4157978/

6. Emont, S. Measuring the Impact of Patient Portals: What the Literature Tells Us. California HealthCare Foundation 2011. Available from: http://www.chcf.org/publications/2011/05/measuring-impact-patientportals

7. Wright A, Feblowitz J, Samal L, McCoy AB, Sittig DF. The Medicare Electronic Health Record Incentive Program: Provider Performance on Core and Menu Measures. Health Services Research 2014; 49: 325-346. Available from: http://www.ncbi.nlm.nih.gov/pubmed/24359554

8. Centers for Medicare \& Medicaid Services. Stage 2 Eligible Professional Meaningful Use Core and Menu Measures. Available from: http://www.cms.gov/Regulations-andGuidance/Legislation/EHRIncentivePro grams/Downloads/Stage2_MeaningfulUseSpecSheet_TableContents_EPs.pdf

9. Office of the National Coordinator for Health Information Technology. U.S. Adoption of Patient Engagement Functionalities. Available from: http://dashboard.healthit.gov/quickstats/pages/FIG-HospitalAdoption-of-Patient-Engagement-Functionalities.php

10. Centers for Medicare \& Medicaid Services. Electronic Health Record Incentive Program - Stage 3 and Modifications to Meaningful Use in 2015 through 2017. Available from: https:/www.federalregister.gov/ articles/2015/10/16/2015-25595/medicare-and-medicaid-programs-electronic-health-record-incentiveprogram-stage-3-and-modifications\#h-105

11.James, J. Health Policy Brief: Medicare Hospital Readmissions Reduction Program. Health Affairs 2013. Available from: http://www.healthaffairs.org/healthpolicybriefs/brief.php?brief_id=102

12. Centers for Medicare \& Medicaid Services [Internet]. Readmissions Reduction Program. Available from:http://www.cms.gov/Medicare/Medicare-Fee-for-Service-Payment/AcuteInpatientPPS/Readmis sions-Reduction-Program.html

13. Institute of Medicine, Committee on Quality of Health Care in America. Crossing the quality chasm: a new health system for the 21st century. Washington, D.C: National Academy Press 2001. Available from: https://iom.nationalacademies.org/ /media/Files/Report\%20Files/2001/Crossing-the-Quality-Chasm/ Quality\%20Chasm\%202001\%20\%20report\%20brief.pdf

14. Ammenwerth E, Schnell-Inderst P, Hoerbst A. The impact of electronic patient portals on patient care: a systematic review of controlled trials. Journal of Medical Internet Research 2012; 14: e162. Available from: http://www.jmir.org/2012/6/e162/

15. Otte-Trojel T, Bont A, Rundall TG, Klundert J. How outcomes are achieved through patient portals: a realist review. Journal of American Medical Informatics Association 2013; 21: 751-757. Available from: http://jamia.oxfordjournals.org/content/21/4/751

16. Otte-Trojel T, Bont A, Klundert J, Rundall TG. Characteristics of Patient Portals Developed in the Context of Health Information Exchanges: Early Policy Effects of Incentives in the Meaningful Use Program in the United States. J Med Internet Res 2014; 16: e258. Available from: http://www.ncbi.nlm.nih.gov/pmc/ar ticles/PMC4260079/

17. University of North Carolina Health System Annual Report 2013. Available from: https://www.unchealth care.org/site/aboutus/annualreport2013.pdf

18. Epic. Mobile Applications and Portals: Integrated Personal Health Record. Available from: http://www. epic.com/software-phr.php.

19. Charlson ME, Pompei P, Ales KL, MacKenzie RC. A new method of classifying prognostic comorbidity in longitudinal studies: development and validation. Journal of Chronic Disease 1987; 40: 373-383. Available from: http://www.ncbi.nlm.nih.gov/pubmed/3558716 
20. Murray SB, Bates DW, Ngo L, Ufberg JW, Shapiro NI. Charlson index is associated with one-year mortality in emergency department patients with suspected infection. Journal of Academic Emergency Medicine 2006; 13: 530-536. Available from: http://www.ncbi.nlm.nih.gov/pubmed/16551775

21. Haun JN, Lind JD, Shimada SL, Martin TL, Gosline RM, Antinori N, Stewart M, Simon SR. Evaluating User Experiences of the Secure Messaging Tool on the Veterans Affairs' Patient Portal System. J Med Internet Res 2014; 16: e75. Available from: http://www.ncbi.nlm.nih.gov/pmc/articles/PMC3961805/

22. Weingart SN, Rind D, Tofias Z, Sands DZ. Who uses the patient internet portal? the PatientSite experience. Journal of the American Medical Informatics Association 2006; 13: 91-95. Available from: http://www.ncbi.nlm.nih.gov/pmc/articles/PMC1380201/

23. Silvestre A, Sue VM, Allen JY. If you build it, will they come? The Kaiser Permanente model of online health care. Health Affairs 2009; 28: 334-344. Available from: http://content.healthaffairs.org/content $/ 28 / 2 / 334$.full

24. Weinberger M, Oddone EZ, Henderson W. Does increased access to primary care reduce hospital readmissions? New Engl J Med 1996; 334: 1441-1447. Available from: http://www.nejm.org/doi/full/ 10.1056/NEJM199605303342206

25. Clemons SK, Bolton K, Freriks G. The effect of patient portals on quality outcomes and its implications to Meaningful Use: A systematic review. J Med Internet Res 2015; 17: e44. Available from: http://www.jmir. $\operatorname{org} / 2015 / 2 / \mathrm{e} 44 /$

26. Irizarry T, DeVito Dabbs A, Curran CR. Patient portals and patient engagement: a state of the science review. J Med Internet Res 2015; 17: e148. Available from: http://www.jmir.org/2015/6/e148/

27.Lyles CR, Sarkar U, Schillinger D, Ralston JD, Allen JY, Nguyen R, Karter AJ. Refilling medications through an online patient portal: consistent improvements in adherence across racial/ethnic groups. J Am Med Inform Assoc 2015; 126. Available from: http://www.ncbi.nlm.nih.gov/pubmed/26335983

28. Sarkar U, Lyles CR, Parker MM, Allen J, Nguyen R, Moffet HH, Schillinger D, Karter AJ. Use of the refill function through an online patient portal is associated with improved adherence to statins in an integrated health system. Med Care 2014; 52: 194-201. Available from: http://www.ncbi.nlm.nih.gov/ pubmed/24374412

29. Tenforde M, Nowacki A, Jain A, Hickner J. The association between personal health record use and diabetes quality measures. J Gen Intern Med 2012; 27: 420-424. Available from: http://www.ncbi.nlm.nih. gov/pmc/articles/PMC3304034/

30. Otte-Trojel T, de Bont A, Rundall TG, van de Klundert J. What do we know about developing patient portals? A systematic literature review. J Am Med Inform Assoc 2015; 114. Available from: http://www.ncbi. nlm.nih.gov/pubmed/26335985

31. Dhanireddy S, Walker J, Reisch L, Oster N, Delbanco T, Elmore JG. The urban underserved: attitudes towards gaining full access to electronic medical records. Health Expect 2014; 17: 724-732. Available from: http://www.ncbi.nlm.nih.gov/pubmed/22738155

32. Hassol A, Walker J, Kidder D, Rokita K, Young D, Pierdon S, Deitz D, Kuck S, Ortiz E. Patient experiences and attitudes about access to a patient electronic health care record and linked web messaging. J Am Med Infor Assoc 2004; 11: 505-513. Available from: http://www.ncbi.nlm.nih.gov/pmc/articles/PMC524631/

33. Ludwin S, Greysen SR. Use of smartphones and mobile devices in hospitalized patients: Untapped opportunities for inpatient engagement. J Hosp Med 2015; 10: 459-461. Available from: http://www.ncbi.nlm. nih.gov/pubmed/25872902 